\title{
Elektrokardiografska ambulatorna dijagnostika u Općoj županijskoj bolnici Požega Ambulatory electrocardiogram diagnostics in County General Hospital Požega
}

\author{
Antonela Čanić', Dajana Perinovićc', Slavica Oberan', Mirela Stapić \\ 'Opća županijska bolnica Požega, Internistička poliklinika, Osječka 32, 34000 Požega, Hrvatska \\ ${ }^{1}$ County General Hospital Požega, Internal Medicine polyclinic, Osječka 32, 34000 Požega, Croatia \\ 2Opća županijska bolnica Požega, Odjel za kardiologiju, Osječka 32, 34000 Požega, Hrvatska \\ ${ }^{2}$ County General Hosipital Požega, Department of Cardiology, Osječka 32, 34000 Požega, Croatia
}

\begin{abstract}
Sažetak
Stupanj težine poremećaja srčane akcije nije uvijek u skladu s kliničkim simptomima. Kada se verificira postojanje i vrsta aritmije, mora se utvrditi i krajnji ishod liječenja.

Prema spoznajama medicine zasnovane na dokazima potrebno je odabrati odgovarajuce metode/postupke liječenja uz obaveznu evaluaciju stupnja rizika, cijene koštanja, stupnja sigurnosti i krajnjih ishoda liječenja. Jedna od osnovnih pretraga za potvrdu racionalne dijagnoze i izbor daljnjeg liječenja uz kvalitetnu anamnezu i klinički pregled elektrokardiografska je ambulatorna dijagnostika [engl. ambulatory electrocardiogram].

Prema do danas publiciranim rezultatima studija koje opisuju istovjetnu problematiku postoji velika vjerojatnost da se s porastom broja učinjenih ambulatornih elektrokardiograma i kvalitetnijom informatičkom obradom snimljenih podataka, povećava dostupnost opisane pretrage, te da će se posljedično povećati broj ambulatornih elektrokardiograma. Opisujemo današnje relevantne podatke u Požeško-slavonskoj županiji. Vidljivo je značajno povećanje broja ambulatornih elektrokardiograma te posljedično povećanje stupnja kvalitete života bolesnika s poremećajima srčanog ritma.
\end{abstract}

Ključne riječi: aritmija • holter • liječenje • prognoza

Kratki naslov: Elektrokardiografska ambulatorna dijagnostika

\begin{abstract}
The degree of severity of cardiac action is not always consistent with clinical symptoms. When verifying the existence and type of arrhythmia, one should determine methods and the final outcome of treatment. According to the medicine knowledge based on evidence it is necessary to choose the appropriate methods and procedures of the course of treatment with a mandatory evaluation of the degree of risk, economic cost of treatment, level of security and the final outcome of treatment. One of the basic tests to confirm the diagnosis and rational selection of further treatment with quality medical history and clinical examination is ambulatory ECG diagnostics [ambulatory electrocardiogram].

According to so far published results of studies that describe identical issues there is a significant likelihood of the increase of the procedure in the number of ambulatory electrocardiogram committed and qualitative information processing of the recorded data, increases the availability of the described method, and permanently increase of the number of ambulatory electrocardiogram. We describe present relevant information in Pozega-Slavonia County. The presented results shown a significant increase in the number of ambulatory electrocardiogram and consequently increase the level of quality of life for patients with heart rhythm disturbances.
\end{abstract}

Keywords: arrhythmia • Holter • treatment • prognosis

Running head: Ambulatory electrocardiogram diagnostics

Received June17 $7^{\text {th }}$ 2016;

Accepted December 11 $11^{\text {th } 2016 ; ~}$

Autor za korespondenciju/Corresponding author: Antonela Čanić, mag. med. techn., County General Hospital Požega, Osječka 32, 34000 Požega, Croatia • Tel: +385 $34254558 \cdot$ Mob: +385 99 41 85624•E-mail:antonela.canic@gmail.com

\section{Uvod / Background}

Srčane aritmije relativno su česte. Neke od njih znače samo neugodu za bolesnika, dok druge, naravno mnogo rjeđe, mogu biti opasne po život ili pak biti pokazatelj nekoga još ozbiljnijeg poremećaja srca ili drugih organa. Jedna od neobičnosti jest činjenica da ozbiljnost aritmije nije uvijek u skladu s njezinim simptomima. Neke od njih koje nisu opasne po život mogu imati neugodne simptome, a one povezane i s rizikom smrti mogu biti u početku bolesniku gotovo nezamjetljive [2]. Treba reći da ima bolesnika koji svoju aritmiju uopće ne primjećuju. Tu nažalost možemo ubrojiti i neke ozbiljne aritmije poput kratkotrajne ventrikulske tahikardije. Dakle, jedna vrsta aritmije u nekih bolesnika može stvoriti zanemarive simptome, a u drugih pak vrlo ozbiljne. I sama mogućnost percepcije (ne)pravilnosti srčanih otkucaja razlikuje se od osobe do osobe. Utvrdi li se postojanje, a zatim i vrsta aritmije, valja utvrditi i njezino prognostičko značenje za bolesnika (na osnovi učinjenih ili čak dodatnih pretraga). Nakon toga treba izabrati racionalan put u liječenju odmjerivši rizike, cijenu, sigurnost i korisnost terapijskog pristupa [3].

Jedan od prvih koraka u ambulantnih bolesnika sa sumnjom na aritmiju jest 24-satno ili 48-satno snimanje EKGa. Tom metodom možemo utvrditi učestalost i složenost poremećaja ritma, odnosno utvrditi je li poremećaj ritma 
uzrok simptomima te ocijeniti i pratiti uspješnost profilakse ili terapije aritmije. Ovom pretragom mogu se dobiti i neki drugi podaci kao što su to elementi za sumnju na bolest koronarnih arterija srca (dinamika ST-segmenta). Indikacije za 24-satno snimanje EKG-a u svrhu otkrivanja ili evaluacije aritmije jesu:

1. simptomi koji su s velikom vjerojatnošću povezani s aritmijom: palpitacije, sinkopa, omaglice

2. stanja koja su povezana s opasnim aritmijama (npr. hipertrofijska kardiomiopatija, oštećenje funkcije lijeve klijetke nakon akutnog infarkta miokarda) pa čak i u asimptomatskih bolesnika, a sve radi procjene prognoze bolesti.

3. potreba za procjenom učinka antiaritmijske profilakse ili terapije

U najvećeg broja bolesnika 24-satni EKG prvi je korak u racionalnoj dijagnostici suspektne srčane aritmije. U nemalog broja bolesnika on ostaje i metoda praćenja razvoja bolesti i uspješnosti liječenja. Nakon što je utvrđeno koju aritmiju bolesnik ima, potrebno je procijeniti njezino značenje, ponajprije u smislu prognoze, ali i ocijeniti u kojoj mjeri njezini simptomi utječu na bolesnikove aktivnosti. Nakon toga donijet će se odluka treba li aritmiju uopće liječiti, i ako treba, koji je terapijski pristup najbolji.

Dijagnostika, a još više liječenja aritmija, područje je koje se trenutno možda i najbrže razvija u kardiologiji. Zadnjih 10ak godina kateterska ablacija radiofrekventnom energijom pružila je izlječenje velikom broju bolesnika, a ugradivi kardioverter-defibrilatori [engl. cardioverter-defibrillators] mnogim su bolesnicima podarili „novi početak“. Takav razvoj, iako sa zakašnjenjem, primjetan je u cijeloj Hrvatskoj, samim time i u našoj Požeško-slavonskoj županiji.

Godine 1982. u našu službu uvedena je holterska dijagnostika prvenstveno kao pretraga koja nam je trebala pomoći kod manjeg broja bolesnika, odnosno kod onih koji su imali jasnu simptomatologiju kompleksnih poremećaja srčanog ritma. Kako naša populacija postaje sve starija, a poznato nam je da starost sa sobom nosi degenerativne bolesti koje se u kardiologiji prvenstveno ogledaju u poremećajima srčanoga ritma i slabosti srčanog mišića, stoga razvoj elektroterapije i elektrodijagnostike ne iznenađuje. Ipak u zadnjih sedam godina svjedoci smo novih postupaka u kardiologiji koje smo ranije rijetko viđali, te sve većeg broja bolesnika, koje nismo imali priliku viđati, a oni danas traže našu skrb.

\section{Ciljevi / Aims}

S obzirom da je razvoj elektrodijagnostike i elektroterapije u svijetu značajan, a u hrvatskim okvirima primjeren trenutnoj gospodarskoj situaciji, odlučili smo prikazati naše rezultate na tom području iz sestrinske perspektive:

Ad 1] Kakvo je stanje elektrodijagnostike i elektroterapije u OŽB-u Požega?

Ad 2] Može li se trenuta situacija poboljšati?

Ad 3] Ima li perspektive sutra?

Broj prikazanih pacijenata relativno je malen za ozbiljniju procjenu situacije u ovom području kardiologije pa iznesene dileme i prikaz trenutne situaciju na području gdje skrbi naša Ustanova nudimo kao naš doprinos rješavanju i poboljšanju trenutnog stanja u dijagnostici i terapiji aritmija.

\section{Metoda / Methods}

U prikaz su uključeni pacijenti kojima je bilo potrebno učiniti holter EKG-a u razdoblju od 1. 1. 2008. do 31. 12. 2015. godine koji su liječeni ili pregledavani na kardiološkom odjelu ili kardiološkoj ambulanti Interne službe Opće županijske bolnice Požega. Podaci za potrebe prikaza prikupljeni su pomoću bolničkog računalskog sustava BIS-a, na temelju dijagnoza po međunarodnoj klasifikaciji bolesti (MKB) i iz dokumentacije koja je nastala tijekom liječenja bolesnika. Tražene varijable unesene su u elektronski zapis ispitanika u programu Microsoft Excel. Podaci dobiveni tijekom ovog praćenja evidentirani su u pregledne tablice iz kojih se mogu i iščitati. Podaci su na kontinuiranoj skali prikazivani kao aritmetička sredina i standardna devijacija, dok su nominalne vrijednosti varijable prikazane kao frekvencija i postotak.

\section{Rezultati / Results}

Prikazujemo rezultate koji su evidentirani, kako je navedeno u metodologiji, kroz posljednjih osam godina. Prikazani rezultati upućuju na evidentan porast broja učinjenih holterskih snimanja po svakoj godini, a od 2010. godine značajnije, što je omogućeno kupovinom većeg broja novih uređaja za snimanje rekordera kao i kupovinom kvalitetnije opreme za analizu snimljenoga materijala. Povećani broj učinjenih pretraga uvjetovao je i porast broja novih elektroterapijskih postupaka, koji su sigurno utjecali na kvalitetu života naših pacijenata. Nakon učinjenih određenih elektroterapijskih postupaka neki od bolesnika više nisu imali potrebu za medikamentoznom antiaritmijskom terapijom što je kod većine njih stvaralo osjećaj izliječenosti. Ovaj osjećaj nekada je bio rezerviran većinom za kirurške bolesnike, jer kirurgija je bila i ostala egzaktna disciplina, no novim metodama liječenja, jednim dijelom to postaje i kardiologija.

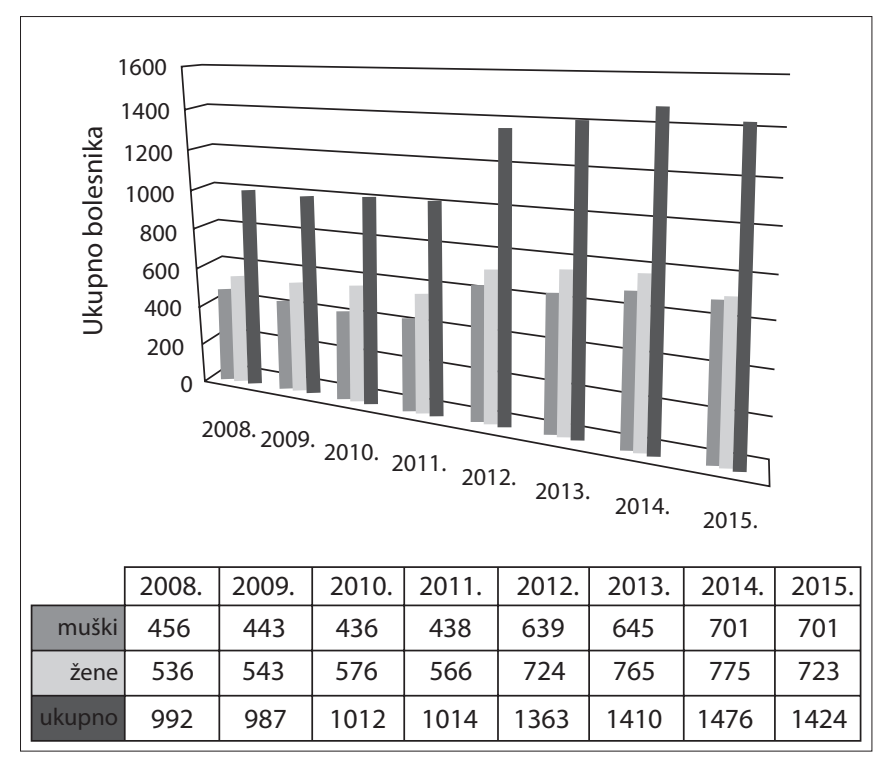

SLIKA [1] Broj učinjenih holterskih pretraga po godinama. 


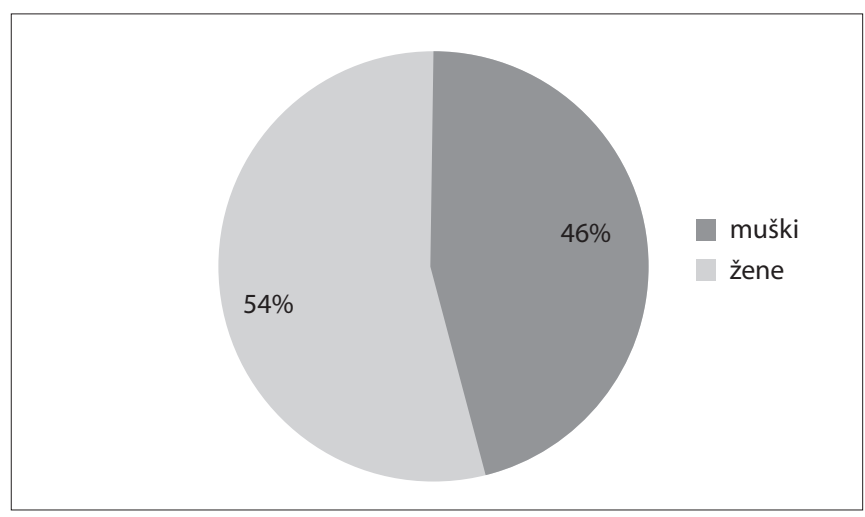

SLIKA [2] Raspodjela svih holterskih pretraga po spolu.

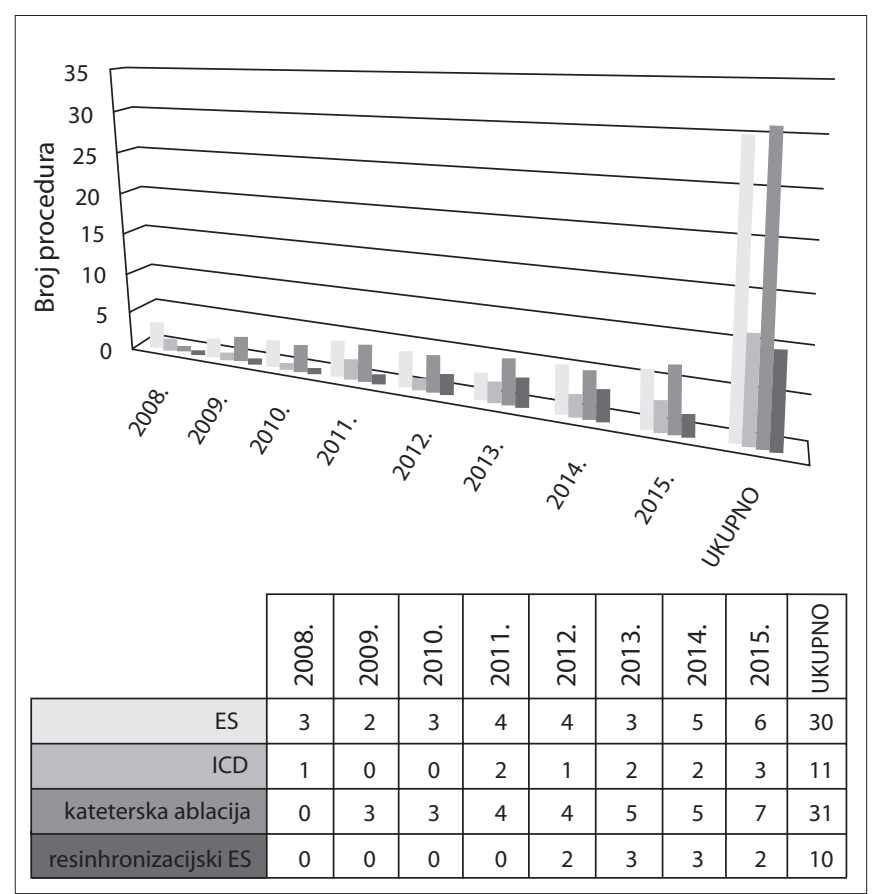

SLIKA [3] Distribucija elektroterapijskih postupaka po godinama.

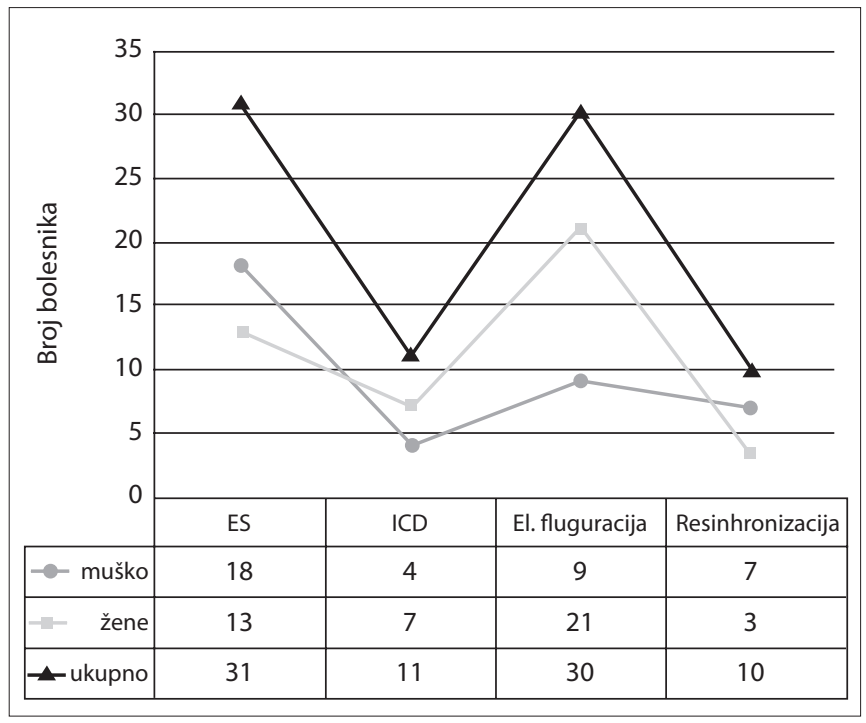

SLIKA [4] Distribucija elektroterapijskih postupaka po spolu.

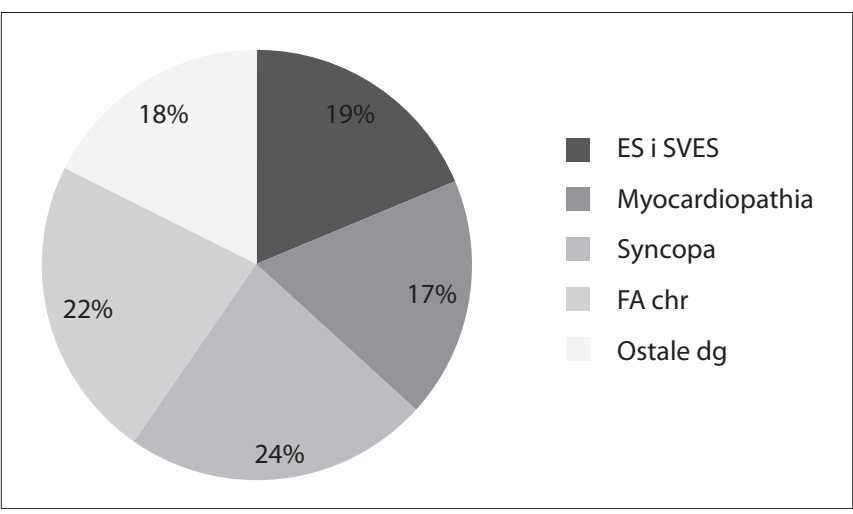

SLIKA [5] Distribucija holtera EKG-a po uputnim dijagnozama.

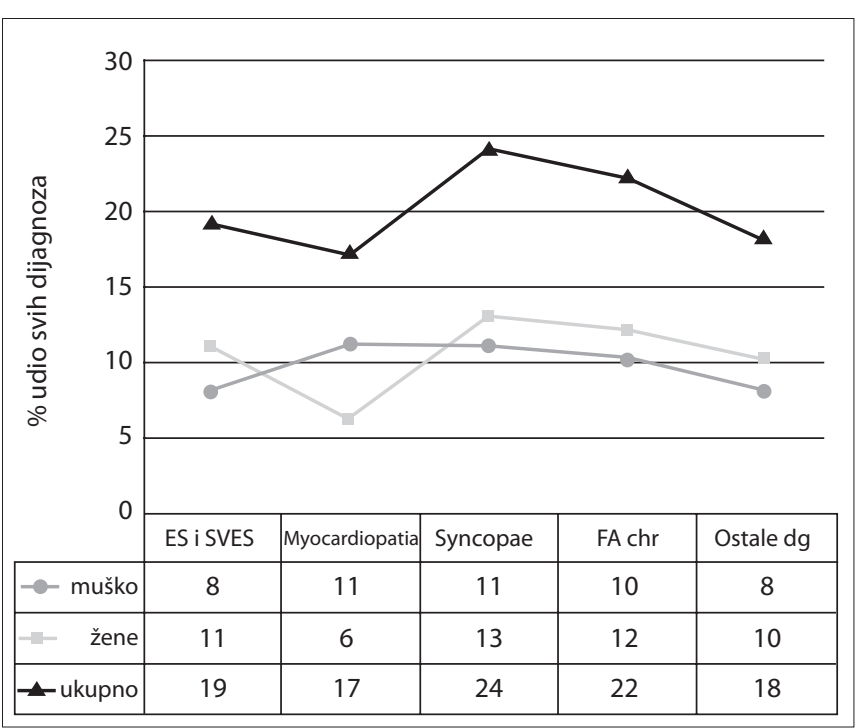

SLIKA [6] Raspodjela holterskih uputnih dijagnoza po spolu.

\section{Rasprava / Discussion}

Zadnjih 10-ak godina kateterska ablacija radiofrekventnom energijom pružila je izlječenje velikom broju bolesnika, a ugradivi kardioverter-defibrilatori mnogima su podarili „novi početak“ $[5,6,7]$. Takav razvoj, iako sa zakašnjenjem, primjetan je kako u cijeloj Hrvatskoj, tako i u našoj regiji. Područje o kojem skrbi OŽB Požega obuhvaća 85.831 stanovnika. Na tom području trenutno skrbimo o 11 bolesnika s ICD-om [engl. cardioverter-defibrillators], a kod 34 bolesnika je nakon elektrofiziološke obrade učinjena kateterska ablacija ranije dijagnosticirane supraventrikulske tahikardije. Šest bolesnika koji boluju od kronične miokardiopatije s niskom ejekcijskom frakcijom imaju resinhronizacijske ES-ove, a kod dvojice je radi poboljšanja ejekcijske frakcije i nemogućnosti drugačijeg postavljanja elektroda, učinjena ugradnja ES-a [engl.electrostimulator] s postavljanjem elektroda na epikard, a ne na endokard što je uobičajeno. Vidljivo je također da 101 bolesnik ima ugrađen elektrostimulator radi atrioventrikularnog bloka. Do 2008. godine bilo ih je registrirano 71. Žene su češći pacijenti kod kojih je učinjeno holtersko snimanje - 54\%, a najčešće uputne 
dijagnoze su sinkopa i kronična fibrilacija atrija, te srčana slabost. Ekstrasistolija, sinkopa i fibrilacija atrija češće su evidentiranekod žena, za razliku od miokardiopatije koja je češće evidentirana kod muškaraca. Proces zdravstvene njege bolesnika s aritmijama zahtijeva temeljitu provedbu sestrinske anamneze i izdvajanje čimbenika koji su ključni u formiranju sestrinske dijagnoze. Sestrinske su dijagnoze opis problema koje sestra prepoznaje kod pacijenata te se na temelju tih problema pristupa definiranju ciljeva i planiranju intervencija. U skrbi za bolesnika s aritmijama vodeće su sestrinske dijagnoze: anksioznost s neizvjesnošću ishoda elektrokardioverzije, neupućenost uslijed nedostatka znanja o tijeku terapijskog postupka, tjeskoba povezana s ishodom, strah od predstojećeg zahvata $[8,9]$. Suvremeni terapijski procesi nameću interdisciplinarni pristup i stalnu edukaciju tima koji se bavi aritmijama.

\section{Zaključak / Conclusion}

Srčane aritmije relativno su česte. Neke od njih znače samo neugodu za bolesnika, dok druge, mnogo rjeđe, mogu biti opasne za život ili pak pokazatelj nekoga još ozbiljnijeg poremećaja srca ili drugih organa. Jedan od prvih koraka u ambulantnih bolesnika i bolesnika na odjelu kod kojih postoji sumnja na aritmiju jest 24-satno ili 48-satno snimanje EKG-a. Tom metodom možemo utvrditi učestalost $i$ složenost poremećaja ritma, odnosno utvrditi je li poremećaj ritma uzrok simptomima te ocijeniti i pratiti uspješnost profilakse ili terapije aritmije. Ovim radom i prikazom naših rezultata željeli smo pokazati da smo prisutni na ovom području kardiologije, da pokušavamo pratiti izazove novog vremena i izazove novih tehnologija.

\section{Authors declare no conflict of interest}

\section{Literatura / References}

[1] Puljević D. Važnost i metode u procjeni rizika maligne aritmije i nagle smrti. Liječ Vjesn 1999;121:188-93.

[2] Rudež I, Unić D, Sutlić Z, Barić D, Legac A, Jonjić D. Surgical treatment of pacemaker lead endocarditis - a case series. 7. Kongres Hrvatskog kardiološkog društva s međunarodnim sudjelovanjem, Opatija, $\mathrm{Hr}$ vatska, 16-19.10.2008., Liječ Vjesn 2008;130 (Suppl.3):30

[3] Sičaja M, Pavlović Zupanc S, Rudez I, Baric D, Unic D, Kranjčec D et al. Cardiac resynchronization therapy - experience from Dubrava University Hospital. 7. Kongres Hrvatskog kardiološkog društva s međunarodnim sudjelovanjem, Opatija, Hrvatska, 16-19.10.2008., Liječ Vjesn 2008;130 (Suppl.3):36

[4] Terasawa T, Balk EM, Chung M, Garlitski AC, Alsheikh-Ali AA, Lau J, et al. Systematic review: comparative effectiveness of radiofrequency catheter ablation for atrial fibrillation. Ann Intern Med. 2009;151:191202.

[5] Polić S, Glavaš D. Neke osobitosti prepoznavanja i liječenja zatajivanja srca u Republici Hrvatskoj. Kardio list. 2011;6(11):286.

[6] Miličić D. Zatajivanje srca. In: Vrhovac B, Jakšić B, Reiner Ž, Vucelić B. Interna medicina. Zagreb. Naklada Ljevak. 2008:459-65

[7] Cindrić Bogdan G. Prevencija srčano-žilnih bolesti. Ordinacija.hr. 2010. Available at: http://www.ordinacija.hr/ zdravlje/kolumna/prevencija-srcano-zilnih-bolesti/: retreived at: 20. Rujna 2016.

[8] Šepec S, Kurtović B, Munko T, Vico M, Abcu Aldan D, Babić D, Turina A. Sestrinske dijagnoze. Zagreb: Hrvatska komora medicinskih sestara; 2011.

[9] Kadović M, Abcu Aldan D, Babić D, Kurtović B, Piškorjanac S, Vico M. Sestrinske dijagnoze 2. Zagreb: Hrvatska komora medicinskih sestara; 2013. 